\title{
THE
}

\section{Temperature compensation of aerobic capacity and performance in the Antarctic pteropod, Clione antarctica, compared with its northern congener, $C$. limacina}

\author{
Agnieszka K. Dymowska \\ University of Rhode Island \\ Thomas Manfredi \\ University of Rhode Island \\ Joshua J. C. Rosenthal \\ Brad A. Seibel \\ University of Rhode Island, seibel@usf.edu
}

Follow this and additional works at: https://digitalcommons.uri.edu/bio_facpubs

Terms of Use

All rights reserved under copyright.

\section{Citation/Publisher Attribution}

Dymowska, A. K., Manfredi, T., Rosenthal, J. J.C., \& Seibel, B. A. (2012). Temperature compensation of aerobic capacity and performance in the Antarctic pteropod, Clione antarctica, compared with its northern congener, C. limacina. Journal of Experimental Biology, 215, 3370-3378. doi: 10.1242/jeb.070607 Available at: http://dx.doi.org/10.1242/jeb.070607

This Article is brought to you for free and open access by the Biological Sciences at DigitalCommons@URI. It has been accepted for inclusion in Biological Sciences Faculty Publications by an authorized administrator of DigitalCommons@URI. For more information, please contact digitalcommons-group@uri.edu. 
The Journal of Experimental Biology 215, 3370-3378 (C) 2012. Published by The Company of Biologists Ltd doi:10.1242/jeb.070607

\title{
RESEARCH ARTICLE
}

\section{Temperature compensation of aerobic capacity and performance in the Antarctic pteropod, Clione antarctica, compared with its northern congener, $C$. limacina}

\author{
Agnieszka K. Dymowska ${ }^{1, *}$, Thomas Manfredi ${ }^{2}$, Joshua J. C. Rosenthal ${ }^{3}$ and Brad A. Seibel ${ }^{1, \dagger}$ \\ ${ }^{1}$ Department of Biological Sciences, University of Rhode Island, Kingston, RI 02891, USA, ${ }^{2}$ Department of Kinesiology, University of \\ Rhode Island, Kingston, RI 02891, USA and ${ }^{3}$ Institute of Neurobiology and Department of Biochemistry, University of Puerto Rico \\ Medical Sciences Campus, San Juan 00901, Puerto Rico \\ ${ }^{*}$ Current address: Biological Sciences, University of Alberta, Alberta, Canada T6G 2E9 \\ ${ }^{\dagger}$ Author for correspondence (seibel@uri.edu)
}

\begin{abstract}
SUMMARY
In ectotherms living in cold waters, locomotory performance is constrained by a slower generation of the ATP that is needed to fuel muscle contraction. Both polar and temperate pteropods of the genus Clione, however, are able to swim continuously by flapping their parapodia (wings) at comparable frequencies at their respective habitat temperatures. Therefore, we expected polar species to have increased aerobic capacities in their wing muscles when measured at common temperatures. We investigated muscle and mitochondrial ultrastructure of Clione antarctica from the Southern Ocean $\left(-1.8^{\circ} \mathrm{C}\right)$ and populations of a sister species, Clione limacina, from the Arctic $\left(-0.5\right.$ to $\left.3^{\circ} \mathrm{C}\right)$ and from the North Atlantic $\left(10^{\circ} \mathrm{C}\right)$. We also measured oxygen consumption and the activity of the mitochondrial enzyme citrate synthase (CS) in isolated wings of the two species. The Antarctic species showed a substantial up-regulation of the density of oxidative muscle fibers, but at the expense of fast-twitch muscle fibers. Mitochondrial capacity was also substantially increased in the Antarctic species, with the cristae surface density $\left(58.2 \pm 1.3 \mu \mathrm{m}^{2} \mu \mathrm{m}^{-3}\right)$ more than twice that found in temperate species $\left(34.3 \pm 0.8 \mu \mathrm{m}^{2} \mu \mathrm{m}^{-3}\right)$. Arctic $C$. limacina was intermediate between these two populations $\left(43.7 \pm 0.5 \mu \mathrm{m}^{2} \mu \mathrm{m}^{-3}\right)$. The values for cold-adapted populations are on par with those found in highperformance vertebrates. As a result of oxidative muscle proliferation, CS activity was 4-fold greater in $C$. antarctica wings than in temperate $C$. limacina when measured at a common temperature $\left(20^{\circ} \mathrm{C}\right)$. Oxygen consumption of isolated wing preparations was comparable in the two species when measured at their respective habitat temperatures. These findings indicate complete compensation of ATP generation in wing muscles across a $10^{\circ} \mathrm{C}$ temperature range, which supports similar wing-beat frequencies during locomotion at each species' respective temperature. The elevated capacity in the wing muscles is reflected in the partial compensation of whole-animal oxygen consumption and feeding rates.
\end{abstract}

Key words: mitochondria, cristae, citrate synthase, cold, temperature, Antarctica.

Received 1 February 2012; Accepted 28 May 2012

\section{INTRODUCTION}

In ectotherms inhabiting cold waters, rates of substrate diffusion and enzymatic activity are constrained by the low temperature (for a review, see Guderley and St-Pierre, 2002). This may result in a decreased capacity for the synthesis of ATP that is used for force generation in locomotory muscles (Clark, 1984). However, in terms of ATP, the cost of muscle contraction is believed to be independent of temperature, being dependent, primarily, on the frequency of muscle contraction (cf. Suarez, 2003). Therefore, locomotory muscles of ectotherms that stay active in cold temperatures may be expected to undergo physiological modifications to increase the aerobic capacity for ATP production (Egginton and Sidell, 1989; Johnston et al., 1998; St-Pierre et al., 1998). Fish and some invertebrates exposed to seasonal or latitudinal reductions in temperature show proliferation of aerobic muscle fibers (Sidell, 1980; Johnston and Maitland, 1980; Tyler and Sidell, 1984) as well as an enhanced metabolic capacity of those fibers via (1) elevated mitochondrial densities (Johnston et al., 1998; Sommer and Pörtner, 2002), (2) increased surface density of folded membranes inside a mitochondrion (cristae) (St-Pierre et al., 1998; Kilarski et al., 1996) and/or (3) mitochondrial enzymatic capacities (Crockett and Sidell,
1990; Kawall et al., 2002). Such modifications presumably enhance aerobic capacity because mitochondria are the primary site of aerobic ATP production. However, mitochondria may also facilitate intracellular oxygen diffusion, which is also constrained in cold water (Sidell, 1998).

Enhanced aerobic capacity as a response to low temperatures is well documented in temperate eurytherms and some Arctic stenotherms (for reviews, see Guderley, 2004; Pörtner, 2002; Pörtner et al., 2009). Similar findings have been reported for Antarctic species (Clarke, 1980; Johnston and Harrison, 1985; Torres and Somero, 1988; Crockett and Sidell, 1990). However, investigations in Antarctic animals have been hampered by the lack of an appropriate comparative system in warmer waters (Weinstein and Somero, 1998). To date, most comparative studies on temperature adaptation have focused on the Notothenioidae (Crockett and Sidell, 1990; Weinstein and Somero, 1998; Hardewig et al., 1999), an abundant group of fishes that is highly endemic to the Southern Ocean, and some benthic invertebrates (Pörtner et al., 1999; Morley et al., 2009; Galarza-Muñoz et al., 2011). Although the studies uncovered substantial evidence of temperature adaptation, the models they used focused on sluggish, 
bottom-dwelling species with little need to up-regulate aerobic capacity (Peck, 2002).

In contrast, gymnosomatous pteropods of the genus Clione are active swimmers with an accessible, well-studied locomotory system (Seibel et al., 2007; Borrell et al., 2005; Satterlie and Spencer, 1985) and a distribution range extending from polar to temperate waters (Gilmer and Lalli, 1990). As such, they are suitable for investigating cold-temperature compensation and adaptation (Seibel et al., 2007; Rosenthal et al., 2009). Clione antarctica in the cold waters of the Southern Ocean is ecologically similar to, and has been described historically as a subspecies of, Clione limacina, which lives in temperate and polar waters in the northern hemisphere. In addition to morphological similarities, both species have similar life histories. They feed exclusively on the thecosomatous pteropod Limacina helicina (Conover and Lalli, 1972; Gilmer and Lalli, 1990), although the northern and southern L. helicina populations are now known to be genetically distinct (Hunt et al., 2010). Both Clione populations swim continuously in the water column by sweeping their highly muscularized parapodia (wings) through an arc of approximately $180 \mathrm{deg}$ at frequencies of $1-2 \mathrm{~Hz}$ (Satterlie et al., 1985; Borrell et al., 2005). Clione spp. are also a unique model in that when the wings and ganglia are dissected free from the rest of the body they maintain rhythmic contractions that approximate those exhibited by adult animals. Thus, the physiological performance of the swim system can be studied independently from the whole animal (Satterlie and Spencer, 1985; Rosenthal et al., 2009).

Locomotor musculature in C. limacina, as investigated previously, includes four layers of muscle bundles consisting of both mitochondria-rich (oxidative) and mitochondria-poor (anaerobic) muscle fibers (Satterlie et al., 1990; Rosenthal et al., 2009). These two types of muscle fibers occupy distinct regions in the muscle bundles, with anaerobic fibers occupying $\sim 50 \%$ of the bundle (Rosenthal et al., 2009). In stark contrast, muscle bundles in the swim musculature of $C$. antarctica consist entirely of oxidative, mitochondria-rich fibers. The anaerobic fibers, as well as the giant swim motoneurons that control contraction of anaerobic fibers in C. limacina, are absent in C. antarctica (Rosenthal et al., 2009). The proliferation of oxidative, mitochondria-rich fibers displaces mitochondria-poor fibers in muscle bundles of $C$. antarctica and presumably offsets the temperature-induced decrease in aerobic capacity (Rosenthal et al., 2009). This increase in oxidative capacity allows $C$. antarctica to achieve activity levels equivalent to those of C. limacina in temperate waters (Seibel et al., 2007). This difference in tissue organization between temperate and Antarctic Clione spp. influences swimming patterns and behavior of both species. Whereas locomotion in C. limacina consists of two distinct 'gears' supported by both oxidative and anaerobic muscle fibers (Satterlie et al., 1990), only a single speed has been observed in $C$. antarctica with no detectable escape response (Gilmer and Lalli, 1990; Borrell et al., 2005; Seibel et al., 2007). When disturbed, $C$. antarctica displays a whole-body withdrawal reflex rather than an increased swimming speed (Norekian and Satterlie, 1996). These different responses to mechanical stimuli are likely related to the differences in locomotory musculature.

In the present study, we further investigate the ultrastructure and energetics of locomotory muscles in C. antarctica from the Southern Ocean in comparison with those in its sister species, C. limacina, from two different locations: one from relatively temperate waters in the North Atlantic and the other from the cold Arctic waters that approximate conditions found in Antarctica. Our previous study revealed that metabolic rates and wing-beat frequencies of $C$. antarctica at $-2^{\circ} \mathrm{C}$ are comparable with those of $C$. limacina at $5^{\circ} \mathrm{C}$
(Seibel et al., 2007). We hypothesize that this is made possible by increased aerobic capacity in the locomotory muscles and enhanced feeding activity. To test our hypothesis, we measured mitochondrial volume densities, mitochondrial cristae surface densities and enzyme activities in isolated wing muscles. We also measured feeding and oxygen consumption rates to determine if the compensation is apparent at the whole-animal level. In parallel, we investigated the effect of laboratory cold-acclimation on locomotory muscle structure in C. limacina. This study presents a thorough comparison of wholeanimal, muscle and mitochondrial energetics, ultrastructure and morphometrics in two highly active ectotherms living across a wide temperature range.

\section{MATERIALS AND METHODS Animals}

Temperate specimens of Clione limacina (Phipps 1774) were collected by hand from the shore in Logy Bay, Newfoundland, Canada during early to mid summer (June and July). The temperature ranged from 5 to $15^{\circ} \mathrm{C}$ depending on local currents and upwelling in the bay. Arctic specimens of $C$. limacina were collected during a research cruise in mid to late summer (July and August) using a plankton net $(0-240 \mathrm{~m}$ depth) in the Hornsund region of the Svalbard archipelago $\left(76^{\circ} 59^{\prime} \mathrm{N}, 15^{\circ} 45^{\prime} \mathrm{E}\right)$. The sea surface temperature ranged between -0.5 and $3^{\circ} \mathrm{C}$, depending on depth. Specimens of Clione antarctica (Smith 1902) were collected by hand from shore in the Ross Sea, near McMurdo Station $\left(77^{\circ} 51^{\prime} \mathrm{S}\right.$, $\left.166^{\circ} 40^{\prime} \mathrm{E}\right)$ and by net-tow in the Weddell Sea $\left(60^{\circ} 56^{\prime} \mathrm{S}, 52^{\circ} 81^{\prime} \mathrm{E}\right)$ in December, during the austral summer [the seawater temperature during the austral summer in McMurdo Sound varies from -1.87 to $-0.5^{\circ} \mathrm{C}$ but is typically near $-1.7^{\circ} \mathrm{C}$ in January (Hunt et al., 2003)]. Upon collection, wings of animals with intact locomotory muscles were dissected and either preserved in $2 \%$ glutaraldehyde in $0.1 \mathrm{moll}^{-1}$ cacodylic acid for electron microscopy (some specimens from all regions) or immediately frozen in liquid nitrogen for subsequent citrate synthase (CS) activity analysis.

Live specimens of temperate $C$. limacina from Newfoundland were incubated at two acclimation temperatures (acclimated specimens in Table 1 ), $10^{\circ} \mathrm{C}$ or $0^{\circ} \mathrm{C}$, for four weeks in temperaturecontrolled rooms at the University of Rhode Island, USA. Throughout incubation, animals were maintained individually in 1liter plastic containers filled with filtered seawater that included streptomycin and ampicillin ( $25 \mathrm{mgl}^{-1}$ each) to control bacterial respiration. Water was changed every second day. Animals were fasted due to the difficulties keeping their exclusive prey, Limacina retroversa and $L$. helicina, in captivity. Clione spp. from both hemispheres are known to have high lipid content, which may help maintain a neutral buoyancy (Phleger et al., 1997) but also facilitates extended fasting periods (up to 260 days) when their exclusive prey are absent (Böer et al., 2005; Böer et al., 2006; Seibel and Dierssen, 2003). Following the incubation period, wings were dissected and preserved as described above.

\section{Quantitative ultrastructural analysis}

Dissected and preserved parapodia of C. limacina and C. antarctica were processed for electron microscopy at JFE Enterprises (Brookeville, MD, USA). Specimen sample sizes were 3 for acclimatized specimens of $C$. limacina and 5 for all other groups (Table 1). Spurr's embedded cross sections of the center of each wing were thin sectioned $(60-90 \mathrm{~nm})$, placed on grids and stained with uranyl acetate and lead citrate. Grids were viewed at $80 \mathrm{kV}$ with a JOEL 12EX Transmission Electron Microscope equipped with a TVIPS high-resolution digital camera (TemCam-F224). 
Table 1. Morphometrics of wing muscles and mitochondria in Clione limacina and Clione antarctica at different temperatures

\begin{tabular}{lccccc}
\hline Species & $N$ & Temperature $\left({ }^{\circ} \mathrm{C}\right)$ & $V_{\mathrm{mf}}(\%)$ & $V_{\text {mit }}(\%)$ & $S_{\mathrm{c}}\left(\mu \mathrm{m}^{2} \mu \mathrm{m}^{-3}\right)$ \\
\hline Clione limacina & & & & & $35.5 \pm 1.4$ \\
Acclimatized & 3 & 10 & $55.3 \pm 3.4$ & $33.3 \pm 1.0$ & $34.3 \pm 0.8$ \\
Acclimated & 5 & 10 & $49.2 \pm 2.1$ & $39.6 \pm 2.1$ & $33.7 \pm 1.1$ \\
Acclimated & 5 & 0 & $50.2 \pm 3.9$ & $33.3 \pm 3.6$ & $43.7 \pm 0.5^{\mathrm{a}}$ \\
Acclimatized & 5 & -0.5 to 3.0 & $48.4 \pm 3.4$ & $36.5 \pm 0.7$ & $58.2 \pm 1.3^{\mathrm{b}}$ \\
Clione antarctica & 5 & -1.7 & $100 \pm 0.0^{\mathrm{a}}$ & \\
Acclimatized & 5 &
\end{tabular}

Values are means \pm s.e.m. Dissimilar letters indicate statistically significant difference from other groups in a column ( $t$-tests, $P<0.05)$.

$V_{\mathrm{mf}}$, volume fractions of oxidative muscle fibers in a muscle bundle; $V_{\text {mit }}$, volume fractions of mitochondria in oxidative muscle fibers; $S_{\mathrm{c}}$, surface density of the mitochondrial cristae.

Micrographs of individual bundles of fibers from oxidative (mitochondria-rich) and anaerobic (mitochondria-poor) muscle were taken at magnifications ranging from 1200 to $1500 \times$. Single oxidative muscle fibers and mitochondria were captured and analyzed at magnifications of $2000-2500 \times$ and $20,000 \times$, respectively, and analyzed according to standard guidelines of stereology (Weibel, 1979). Micrographs of 4-6 representative muscle bundles were obtained for each animal. Within one muscle bundle, micrographs of 4-6 representative oxidative muscle fibers and of 4 representative mitochondria were captured. The micrographs were analyzed with Image-J software (National Institutes of Health, USA), with the use of grid, and cell-counter plugins. Using the point-counting method of Weibel (Weibel, 1979), a grid system was superimposed over each micrograph, and the intersections (points, $P$ ) that hit the microstructure of interest were counted. Volume fractions or densities $(V)$ of oxidative muscle fibers $(\mathrm{mf})$ in a muscle bundle $\left(V_{\mathrm{mf}}\right)$ and mitochondria (mit) in oxidative muscle fibers $\left(V_{\text {mit }}\right)$ were calculated by dividing the number of points that hit the microstructure of interest $(P)$ by the total number of test points $(T)$ :

$$
V=P / T \text {. }
$$

Surface density $(S)$ of the mitochondrial inner membrane, or cristae (c), $\left(S_{\mathrm{c}} ; \mu \mathrm{m}^{2} \mu \mathrm{m}^{-3}\right)$ was calculated using a parallel line test system (Elias and Hyde, 1980):

$$
S_{\mathrm{c}}=2 P / L,
$$

where $L$ is the total length of lines contained within the mitochondrion.

\section{Citrate synthase activity}

Sets of wings were dissected from experimental animals, weighed on a microbalance while frozen and then homogenized in 1:10 parts weight/volume dilution of $0.01 \mathrm{moll}^{-1}$ Tris grinding buffer ( $\mathrm{pH} 7.5$ at $10^{\circ} \mathrm{C}$ ) in hand-held homogenizers (Wheaton, Millville, NJ, USA) kept on ice. Homogenate was centrifuged at $3800 \mathrm{~g}$ for $10 \mathrm{~min}$ at $5^{\circ} \mathrm{C}$. Activity of $\mathrm{CS}$ was assayed under non-limiting substrate conditions as previously described (Thuesen and Childress, 1994; Seibel et al., 1998).

$25 \mu 1$ aliquots of homogenate supernatant were placed in quartz cuvettes in a medium containing a $1 \mathrm{ml}$ solution of $50 \mathrm{mmoll}^{-1}$ imidazole/ $\mathrm{HCl}$ buffer ( $\mathrm{pH} 8$ at $20^{\circ} \mathrm{C}$ ), $0.1 \mathrm{mmoll}^{-1}$ acetyl-CoA, $0.1 \mathrm{mmoll}^{-1}$ 5,5-dithiobis (2-nitrobenzoic acid) (DTNB), $1.5 \mathrm{mmoll}^{-1} \mathrm{MgCl}_{2}$ and $0.5 \mathrm{mmoll}^{-1}$ oxaloacetate. Citrate synthase (E.C. 2.3.3.1) activity was measured as the increase in absorbance at $412 \mathrm{~nm}$, which results from the interaction of reduced CoA with DTNB, using a Shimadsu UV 1700 spectrophotometer (Columbia, $\mathrm{MD}, \mathrm{USA}$ ) equipped with a water-jacketed cuvette holder connected to a recirculating water bath. Measurements were carried out at $20^{\circ} \mathrm{C}$. This temperature was previously shown to be below the denaturation temperature for this enzyme in pteropods (B.A.S., unpublished). Background activities were measured without the presence of oxaloacetate and subtracted from total activities to compute true CS activities in the samples. Enzyme activities are expressed as units (micromoles of substrate converted to product per min) per gram wet mass of tissue.

\section{Oxygen consumption in isolated wing nerve-muscle preparation}

Reduced preparations were made by dissecting specimens of each species in filtered seawater such that only the wings, wing nerves and the central ring ganglia remained. These structures were pinned in a dish coated with Sylgard (Dow Corning, Midland, MI, USA) using cactus spines. A section of the Sylgard ${ }^{\circledR}$ to which the preparation was pinned was excised and placed in a water-jacketed $300 \mu$ l chamber with an integrated Clark-type oxygen electrode (Strathkelvin Instruments, North Lanarkshire, UK). The chamber was filled with filtered seawater. We recorded the oxygen consumption rates of reduced preparations from each species near their respective habitat temperatures $\left(-1.5^{\circ} \mathrm{C}\right.$ and $\left.5^{\circ} \mathrm{C}\right)$. We have shown previously that the swim system of both species spontaneously shifts between slow and fast modes (Rosenthal et al., 2009), presumably due to the intermittent release of endogenous serotonin. Experiments were performed with or without $50 \mu \mathrm{moll}^{-1}$ serotonin (5'-hydroxytryptophan, 5-HT). The application of exogenous serotonin forces the preparation exclusively into the fast mode, resulting in higher rates of oxygen consumption. Additional measurements were made with the wing nerves cut as a control. The contraction of pteropod wings depends on hydrostatic pressure generated by the entire body during locomotion (Arshavsky et al., 1990). Thus, in the reduced preparation, complete wing-beat cycles were not possible. Our measurements therefore cannot correspond to a real measure of performance in nature but rather provide an additional comparison of aerobic performance under identical conditions at different temperatures. The wing nerve-muscle preparations consumed oxygen in proportion to the amount of available oxygen in the chamber (i.e. oxyconformation). Therefore, only data at oxygen concentrations greater than $75 \%$ saturation were used in the analysis of temperature compensation. The runs typically lasted $1.5 \mathrm{~h}$.

\section{Rates of prey consumption}

Individual $C$. antarctica were placed in filtered seawater in sealed 1-liter BOD bottles with five individual prey (Limacina helicina forma antarctica). The bottles were placed in a static water table connected to the flow-through seawater system at McMurdo Station, Antarctica. The temperature was maintained at $-1.8^{\circ} \mathrm{C}$. 
Each day, the numbers of prey consumed were noted, and empty prey shells were removed and measured. Approximately $50 \%$ of the water was exchanged daily to maintain seawater quality. The relationships reported by Seibel et al. between shell diameter and wet, dry and ash-free dry mass (Seibel et al., 2007) were used to estimate the mass of consumed prey each day. The animals used to develop those relationships were collected at the same time, from the same population as those used in the present feeding experiments. Ash-free dry masses allowed subtraction of the shell mass from the consumed prey mass. The feeding rates for similarly sized specimens of $C$. limacina at $5^{\circ} \mathrm{C}$ were calculated from relationships that were developed by Conover and Lalli (Conover and Lalli, 1972) using a similar experimental protocol.

\section{Statistics}

All results are expressed as means \pm s.e.m. or s.d. (feeding experiments). Statistically significant differences in ultrastructure of muscle bundles, fibers and mitochondria, as well as in citrate synthase activity between species, were determined using one-way analysis of variance (ANOVA) tests using the statistical program, Statview v.5 (SAS Institute Inc., San Francisco, CA, USA). In all instances, $P<0.05$ was used as the level of significance, and multiple comparisons were performed using Student-Newman-Keuls tests.

\section{RESULTS}

\section{Ultrastructure of locomotory muscles}

The results of quantitative measurements of volume density of oxidative, mitochondria-rich locomotory muscle fibers $\left(V_{\mathrm{mf}}\right)$, volume density of mitochondria $\left(V_{\text {mit }}\right)$ and surface density of mitochondrial inner membrane $\left(S_{\mathrm{c}}\right)$ are shown in Table $1 . V_{\mathrm{mf}}$ did not differ significantly between muscle bundles of $C$. limacina species, regardless of acclimation or acclimatization temperature (Fig. 1). The oxidative muscle fibers comprised roughly half of the entire bundle (from $48 \%$ to $55 \%$ ) in all four examined groups. Fourweek exposure of $C$. limacina to $0^{\circ} \mathrm{C}$ in the laboratory, as well as seasonal acclimation to cold temperature in the wild, did not result in proliferation of oxidative muscle fibers in the muscle bundles (Fig. 1). This is in contrast to C. antarctica, chronically exposed to the cold $\left(-1.86^{\circ} \mathrm{C}\right)$, which have muscle bundles composed entirely of mitochondria-rich muscle fibers (Rosenthal et al., 2009).

Mitochondrial abundances in muscle fibers were not affected by exposure to cold temperature in any of the studied animals. No significant difference in $V_{\text {mit }}$ existed among the different acclimation and acclimatization temperature groups of $C$. limacina. Similarly, no significant difference in $V_{\text {mit }}$ existed between $C$. limacina and C. antarctica. $V_{\text {mit }}$ for all tested animals was approximately $36 \%$ (Table 1).

In contrast, long-term exposure to cold results in proliferation of the inner mitochondrial membrane (Fig. 2). $S_{\mathrm{c}}$ was similar for $C$. limacina acclimated to $10^{\circ} \mathrm{C}$ and $0^{\circ} \mathrm{C}$ as well as for C. limacina acclimatized to $10^{\circ} \mathrm{C}$ and it ranged from $34.3 \pm 0.8$ to $36.2 \pm 0.2 \mu \mathrm{m}^{2} \mu \mathrm{m}^{-3}$. However, in C. limacina acclimatized to -0.5 to $3^{\circ} \mathrm{C}, S_{\mathrm{c}}$ was approximately $27 \%$ higher compared with $10^{\circ} \mathrm{C}$ acclimatized animals. In $C$. antarctica, $S_{\mathrm{c}}$ was $58.2 \pm 1.3 \mu \mathrm{m}^{2} / \mu \mathrm{m}^{3}$, a value $170 \%$ greater than in $C$. limacina at $10^{\circ} \mathrm{C}$. The morphometric data of each species is presented in comparison to Antarctic fishes, mammals and active fish predators in Fig. 3.

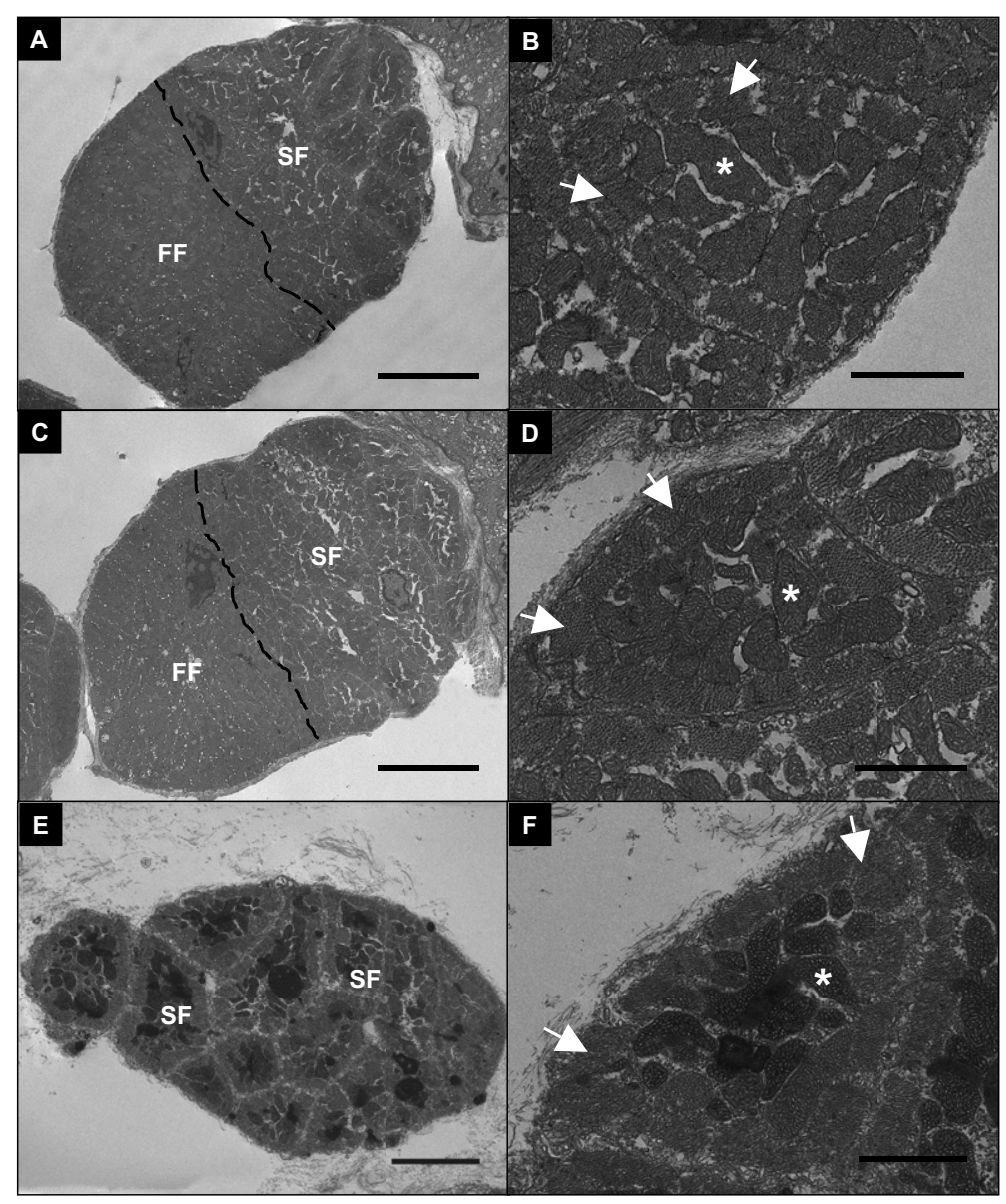

Fig. 1. Representative transmission electron micrographs showing muscle ultrastructure of Clione wings. Panels A, C and E show muscle bundle ultrastructure: $(A) C$. limacina from Newfoundland acclimatized to $10^{\circ} \mathrm{C}$; (C) C. limacina from the Arctic acclimatized to -0.5 to $3^{\circ} \mathrm{C}$; (E) C. antarctica from the Antarctic acclimatized to $-1.86^{\circ} \mathrm{C}$. Slow (aerobic) muscle fibers (SF) occupy roughly half of the muscle bundle in $C$. limacina from Newfoundland and the Arctic. The remaining area consists of fast (anaerobic) muscle fibers (FF). In $C$. antarctica, fast muscle fibers are absent. Panels $\mathrm{B}, \mathrm{D}$ and $\mathrm{F}$ show slow muscle fiber ultrastructure: $(\mathrm{B})$ C. limacina from Newfoundland; (D) C. limacina from the Arctic; (F) $C$. antarctica. The central core of the slow fibers is comprised of mitochondria (asterisk), and is surrounded by myofibrils (arrows). The amount of mitochondria in the slow muscle cells is equivalent regardless of the acclimation temperature or the species. Scale bar: $10 \mu \mathrm{m}(A, C, E) ; 2 \mu \mathrm{m}(B, D, F)$. Panel $E$ is reproduced from Rosenthal et al. (Rosenthal et al., 2009) with permission. 


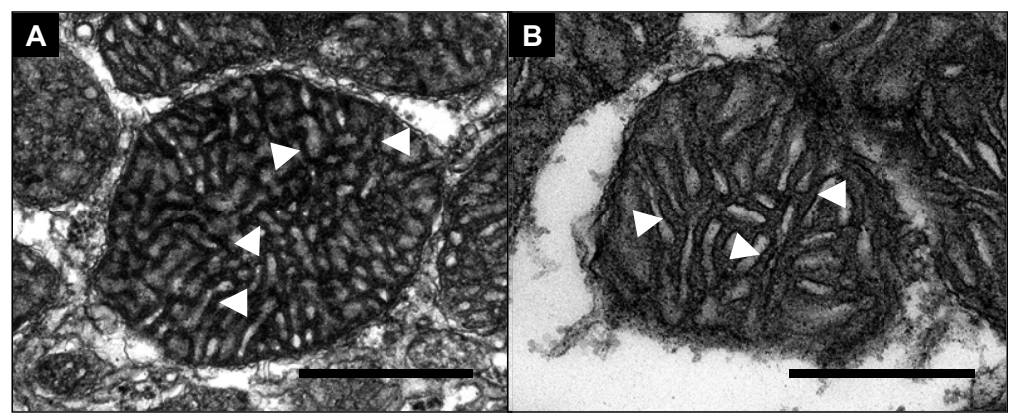

Fig. 2. Representative transmission electron micrographs showing ultrastructure of mitochondria in slow muscle fibers in the wings of Clione antarctica from the Antarctic acclimatized to $-1.86^{\circ} \mathrm{C}(\mathrm{A})$ and Clione limacina from Newfoundland acclimatized to $10^{\circ} \mathrm{C}(\mathrm{B})$. Note the increased cristae of the inner membrane (indicated by arrows) in C. antarctica. Scale bars: $0.5 \mu \mathrm{m}$.

\section{Citrate synthase assay}

The activity of CS measured in the wing tissue of $C$. limacina acclimatized to $10^{\circ} \mathrm{C}$ and $C$. antarctica acclimatized to $-1.8^{\circ} \mathrm{C}$ is presented in Fig. 4. CS activity (units $\mathrm{g}^{-1}$ wet mass) was approximately four times higher in $C$. antarctica than in acclimatized and acclimated $C$. limacina. This result is consistent with differences in the muscle ultrastructure between the two species. No significant difference in $\mathrm{CS}$ activity was observed between $0^{\circ} \mathrm{C}$-acclimated and $10^{\circ} \mathrm{C}$-acclimated and $10^{\circ} \mathrm{C}$-acclimatized $\mathrm{C}$. limacina, which indicates no effect of short-term exposure to cold on CS activity in wing muscle. The activity of CS was not measured in the Arctic $C$. limacina, as we obtained only preserved specimens from that region.

\section{Oxygen consumption in isolated wing nerve-muscle preparation}

Oxygen consumption rates of isolated wing-nerve preparations without addition of serotonin ranged from 0.64 to $1.31 \mu$ moles $\mathrm{O}_{2} \mathrm{~g}^{-1} \mathrm{~h}^{-1} \quad$ for $\quad C$. antarctica (mean $=0.779 \pm 0.29 \mu$ moles $\mathrm{O}_{2} \mathrm{~g}^{-1} \mathrm{~h}^{-1}$; wing mass 3.5-9.1 mg, $N=5$, at $-1.5^{\circ} \mathrm{C}$ ) and from 0.86 to $1.28 \mu$ moles $\mathrm{O}_{2} \mathrm{~g}^{-1} \mathrm{~h}^{-1}$ for $C$. limacina (mean $=1.087 \pm 0.21 \mu$ moles $\mathrm{O}_{2} \mathrm{~g}^{-1} \mathrm{~h}^{-1}$; wing mass $3.0-5.0 \mathrm{mg}, N=3$, at $5.0^{\circ} \mathrm{C}$; Fig. $5 \mathrm{~A}$ ). Application of $50 \mathrm{mmoll}^{-1}$ serotonin in seawater increased oxygen consumption by about 2-fold for $C$. antarctica (mean $=1.68 \pm 0.30 \mu$ moles $\mathrm{O}_{2} \mathrm{~g}^{-1} \mathrm{~h}^{-1}, N=3$ ) but much less in $C$. limacina (1.5 and $1.34 \mu$ moles $\left.\mathrm{O}_{2} \mathrm{~g}^{-1} \mathrm{~h}^{-1}, N=2\right)$. The oxygen consumption rates of $C$. limacina at $5^{\circ} \mathrm{C}$ are not significantly higher than those of $C$. antarctica at $-1.5^{\circ} \mathrm{C}$, in agreement with measurements for the whole animal (Fig. 5B) (Seibel et al., 2007). Limited sample size restricts statistical power for experiments with serotonin.

\section{Rates of prey consumption}

In L. helicina forma antarctica $(2-16 \mathrm{mg}$ wet mass, $N=25)$, dry mass $(D M)$ was related to wet mass $(M)$ as $\ln (D M)=-1.26+0.87 \ln (M)$ $\left(R^{2}=0.92\right)$, ash-free dry mass is equal to $0.38 \ln (M)+0.16\left(R^{2}=0.65\right)$, and wet mass is related to shell diameter $(D)$ as $M=-0.53+1.91 \ln (D)$ $\left(R^{2}=0.86\right)$ (Seibel et al., 2007). The relationships were all significant $(P<0.05)$. Limacina helicina of intermediate sizes $(\sim 5-12 \mathrm{mg}$ wet mass) were used as prey in feeding experiments (uneaten prey were not measured). Large $C$. antarctica $(10.5 \pm 0.13 \mathrm{mg}$ dry mass, $N=13)$ were chosen for feeding experiments. They consumed $0.28 \pm 0.08 \mathrm{mg}$ dry mass (mean \pm s.d.) of $L$. helicina per day at $-1.8^{\circ} \mathrm{C}$ (Fig. 6 ). Conover and Lalli (Conover and Lalli, 1972) reported a feeding rate on L. helicina forma rangi of about $50 \%$ less at $5^{\circ} \mathrm{C}$ for C. limacina (10 mg dry mass) (Fig. 6).

\section{DISCUSSION}

We observed increased cristae surface density and elevated activity of the mitochondrial enzyme, citrate synthase, in locomotory muscles of $C$. antarctica compared with $C$. limacina. In combination with the previously reported proliferation of oxidative muscle fibers, this clearly shows that aerobic capacities are up-regulated in C. antarctica, relative to warmer acclimatized $C$. limacina. Moreover, the difference between the polar and subpolar populations of $C$. limacina suggests a continuum of aerobic capacity related to temperature. The differences in muscle and mitochondrial structure were reflected in oxygen consumption rates of isolated wing-nerve preparations that were higher
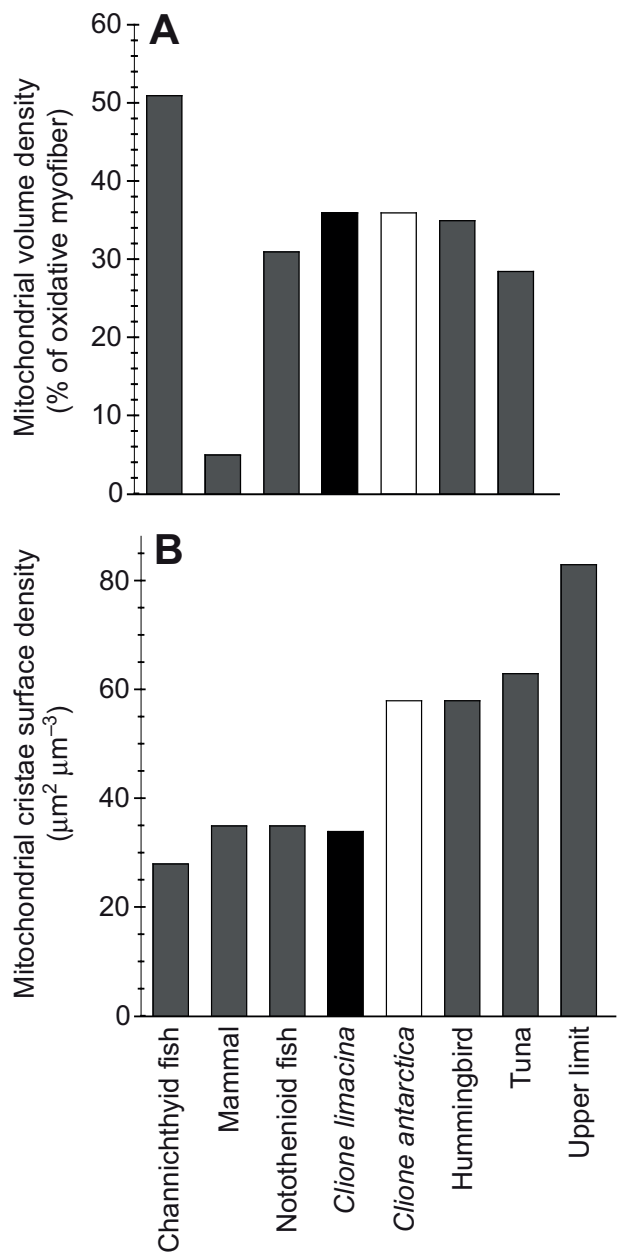

Fig. 3. (A) Volume density of mitochondria within a muscle fiber (\%) and (B) surface density of mitochondrial inner membrane $\left(\mu \mathrm{m}^{2} \mu \mathrm{m}^{-3}\right)$, or cristae, in wing muscles of Clione antarctica (open bars) and Clione limacina (black bars) in comparison to locomotory muscles of polar and 'high-performance' animals (grey bars). Included are polar fishes [Chanychthyid and Notothenioid (O'Brien et al., 2003)], mammals (Hoppeler and Lindstedt, 1985), hummingbirds (Suarez et al., 1991) and tuna (Mathieu-Costello et al., 1992). The upper limit to mitochondrial surface density, hypothesized by Srere (Srere, 1985), is based on a constraint imposed by the space between cristae for mitochondrial matrix enzymes. 


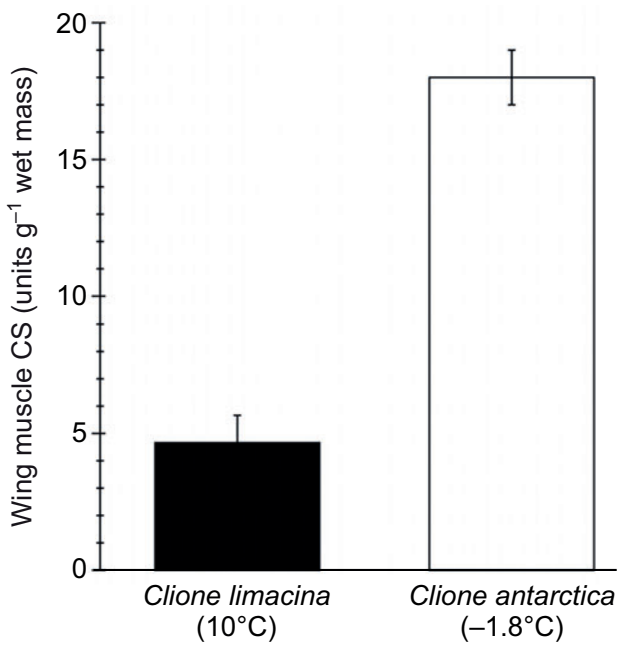

Fig. 4. Citrate synthase (CS) activity in wing muscle tissue of Clione limacina acclimatized to $10^{\circ} \mathrm{C}$ (filled bar) and Clione antarctica (open bar) acclimatized to $-1.8^{\circ} \mathrm{C}$. Acclimation of $\mathrm{C}$. limacina to either 10 or $0^{\circ} \mathrm{C}$ for one month had no significant effect on CS activity (data not shown). Values are means \pm s.e.m.

in the Antarctic species despite a much lower measurement temperature. However, laboratory acclimation of temperate $C$. limacina to cold did not result in ultrastructural changes in locomotory muscles, suggesting that modifications in $C$. antarctica are not a result of temperature-induced phenotypical plasticity but rather reflect permanent adaptation of this population to cold.

\section{Muscle ultrastructure}

In most eurythermal fish, increased mitochondrial volume densities in muscle fibers presumably compensate for a reduction in rates of aerobic ATP synthesis during exposure to cold (for reviews, see Pörtner, 2002; Guderley, 2004). For instance, striped bass, Morone saxatilis, acclimated to $5^{\circ} \mathrm{C}$ (for 8 weeks) show a $57 \%$ increase in $V_{\text {mit }}$ in oxidative muscles compared with $25^{\circ} \mathrm{C}$ acclimated fish (Egginton and Sidell, 1989). Similar results have also been observed for cold-acclimated crucian carp, Carassius carassius, and goldfish, Carassius auratus (Johnston and Maitland, 1980; Tyler and Sidell, 1984). Elevated mitochondrial densities are also found in some stenothermal organisms such as Antarctic fishes (Johnston et al., 1998; O'Brien et al., 2003) and in SubArctic lugworm, Arenicola marinara (Sommer and Pörtner, 2002). These findings suggest that mitochondrial proliferation is a common strategy to compensate for cold. Thus, we were initially surprised not to find significant differences in mitochondrial volume densities in oxidative muscle fibers of polar and temperate pteropods (Clione spp.). In all investigated populations, mitochondria occupy approximately $36 \%$ of a muscle fiber volume regardless of temperature (Table 1). Since a theoretical upper limit to mitochondrial volume density in locomotory muscles may exist, beyond which force generation and contractile function of muscle fibers would be impaired (Weibel, 1985; Suarez et al., 1991; Rome and Lindstedt, 1998), Clione spp. might not be able to increase their aerobic capacity via further mitochondrial proliferation. This is supported by the fact that mitochondrial volume densities found in Clione spp. (Fig. 3) are on par with those found in the flight muscle of hummingbirds $(\sim 35 \%)$, honeybee $(\sim 43 \%)$ (Suarez et al., 1991; Suarez et al., 2000) and blowfly ( 43\%) (Smith, 1963). Mitochondrial densities in the fibers of Clione spp. may be close to maximal values where further increases would result in decreased sustained swimming and foraging performance (Rome and Lindstedt, 1998). However, the increase in the proportion of oxidative muscle fibers $[100 \%$ in $C$. antarctica and $55 \%$ in $C$. limacine (Rosenthal et al., 2009)] in the Antarctic congener means that the total mitochondrial abundance in wing muscle is much greater than in the temperate species.
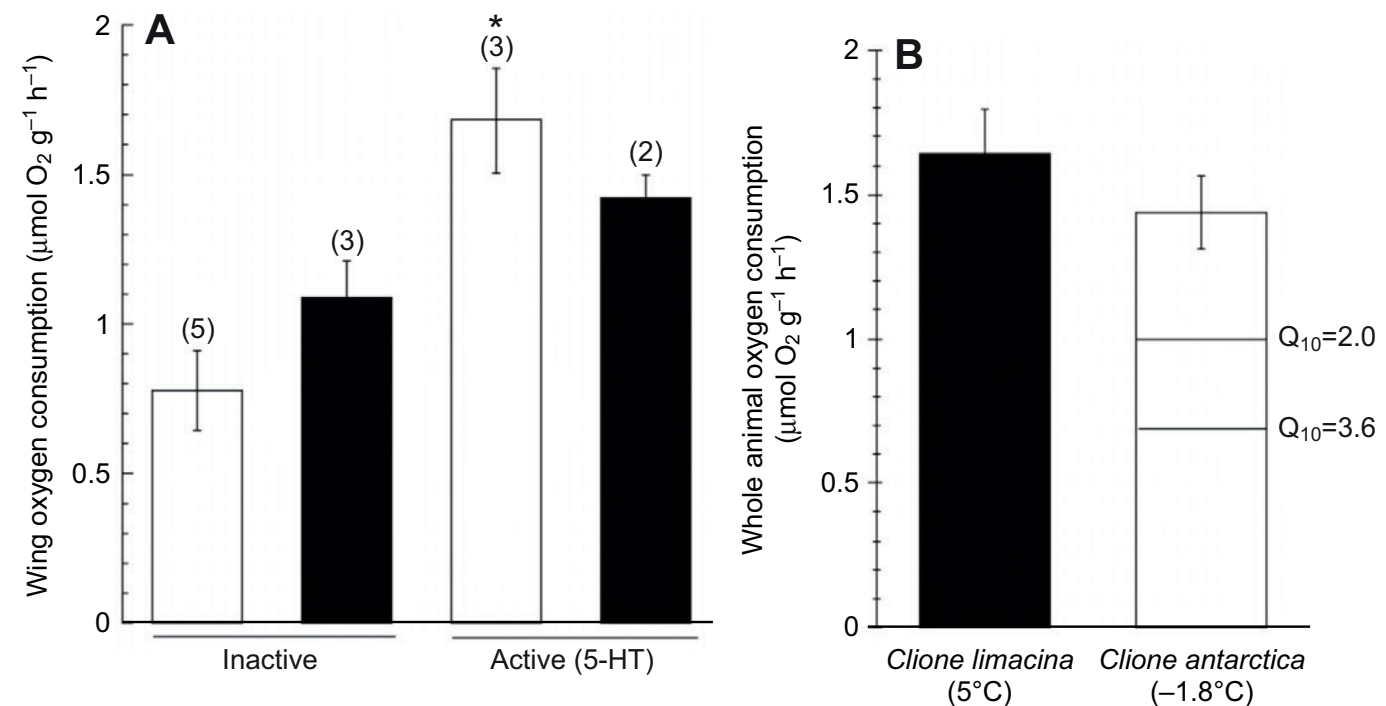

Fig. 5. Oxygen consumption rates for Clione antarctica at $-1.8^{\circ} \mathrm{C}$ (open bars) and Clione limacina at $5^{\circ} \mathrm{C}$ (filled bars). Clione limacina specimens were those acclimatized to $10^{\circ} \mathrm{C}$ although environmental temperature variation for the population includes $5^{\circ} \mathrm{C}$. (A) Isolated wing nerve-muscle preparations during routine activity and during high activity induced with bath application of serotonin $\left(50 \mathrm{mmoll}^{-1} 5-\mathrm{HT}\right)$. Values are means \pm 1 s.e.m., and sample sizes are indicated in parentheses over each bar for isolated wing nerve-muscle preparations. An asterisk indicates statistical difference between the two species in the 5-HT experiment. (B) Whole-animal rates normalized to a common body mass using significant scaling relationships measured for each species (data from Seibel and Dierssen, 2003; Seibel et al., 2007). Error bars represent the range of values calculated using the standard error for the slope of the scaling relationships. The black lines across the open bar represent the rate for $C$. limacina normalized to $-1.8^{\circ} \mathrm{C}$ assuming a typical temperature coefficient $\left(Q_{10}\right)$ of 2.0 and using the measured $Q_{10}$ of 3.6 (Seibel et al., 2007). 


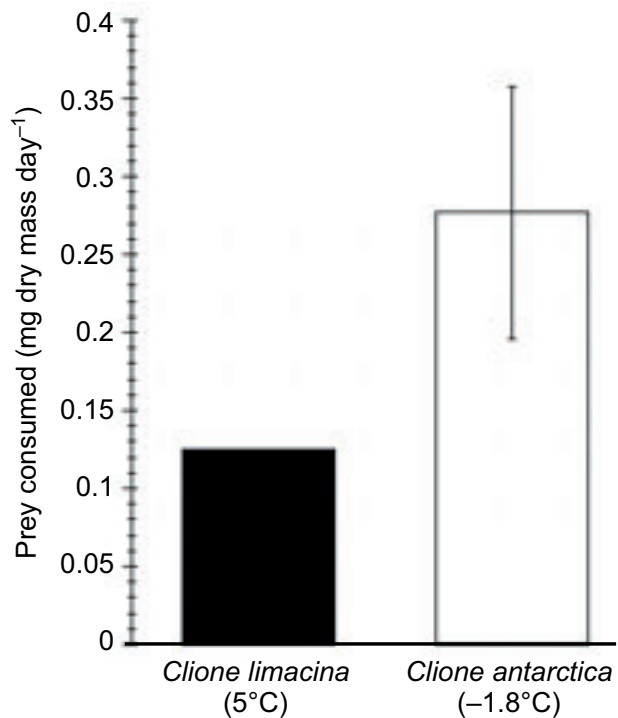

Fig. 6. The rate of consumption ( $\mathrm{mg}$ dry mass day ${ }^{-1}$ ) of the sole prey, Limacina helicina (thecosomatous pteropod), by Clione limacina at $5^{\circ} \mathrm{C}$ (filled bar) (calculated from Conover and Lalli, 1974) and C. antarctica (open bar) at $-1.8^{\circ} \mathrm{C}$. Prey tissue mass was estimated by measurement of the prey's shell diameter, which correlates with dry mass and ash-free dry mass according to relationships reported previously (Seibel et al., 2007). The error bar represents the standard deviation $(N=13)$.

Interestingly, the proportion of oxidative muscle fibers in locomotory muscle bundles of Arctic $C$. limacina did not differ from that in temperate $C$. limacina (Table 1). Also, proliferation of oxidative muscle fibers did not occur during laboratory acclimation (4 weeks) of temperate $C$. limacina to $0^{\circ} \mathrm{C}$ (Table 1 ). These findings suggest that, in contrast to $C$. antarctica, there may exist strong selection for maintenance of the 2-geared swimming system in $C$. limacina during cold exposure. Although not yet described, preliminary observations reveal a latitudinal dichotomy of swimming behaviors in the prey species, L. helicina, similar to that reported here for Clione spp. (B.A.S., unpublished observations). Thus, we believe that a regressed locomotory system (i.e. lack of burst swimming ability) in $C$. antarctica is an example of a temperaturemediated 'disarmament' of predator and prey in a highly co-evolved predator-prey 'arms race'.

\section{Mitochondrial ultrastructure}

It seems that in both $C$. antarctica and Arctic C. limacina, compensation of muscle aerobic capacity is achieved by an increase in mitochondrial cristae surface density rather than mitochondrial proliferation. Although this strategy has been demonstrated during cold acclimation of crucian carp (Kilarski et al., 1996) and rainbow trout (St-Pierre et al., 1998), it has not been found in Antarctic and Sub-Antarctic fishes (Johnston et al., 1998; Guderley and St-Pierre, 2002). However, it is difficult to confirm the finding in the Antarctic fishes as the temperate species to which they are compared often have a different body-form, mode of swimming and activity pattern (Johnston and Harrison, 1985). Cristae surface density was $70 \%$ higher in $C$. antarctica and $27 \%$ higher in the polar C. limacina when compared to the temperate $C$. limacina (Table 1). The cristae surface densities in $C$. antarctica and Arctic $C$. limacina are higher than values reported for mammalian skeletal muscle $\left(20-40 \mu \mathrm{m}^{2} \mu \mathrm{m}^{-3}\right)$ (Hoppeler and Lindstedt, 1985) but lower than the values found in tuna red muscle $\left(63-70 \mu \mathrm{m}^{2} \mu \mathrm{m}^{-3}\right)$ (Mathieu-
Costello et al., 1992). Interestingly, the value obtained for $C$. antarctica is identical to those previously reported for hummingbird flight muscle $\left(58 \mu \mathrm{m}^{2} \mu \mathrm{m}^{-3}\right)$ (Suarez et al., 1991). It appears that cristae surface density in mitochondria of $C$. antarctica is approaching the theoretical upper limit of $83 \mu \mathrm{m}^{2} \mu \mathrm{m}^{-3}$ (Srere, 1985). Higher values may leave insufficient room for Kreb's cycle enzymes in the mitochondrial matrix.

Although some studies have found no obvious correlation between mitochondrial cristae surface density and mitochondrial oxidative capacity (Moyes et al., 1992; Johnston et al., 1998), more cristae provide more surface area for electron transport to occur within a mitochondrion (St-Pierre et al., 1998), which should provide greater total capacity for ATP synthesis. This interpretation is consistent with the high cristae surface densities reported for highperformance animals mentioned above. O'Brien et al. found higher mitochondrial volume densities in icefishes lacking hemoglobin compared to their red-blooded counterparts (O'Brien et al., 2003). However, the mitochondria themselves had lower cristae surface density such that the total surface density per unit mass was relatively constant between these groups. They concluded that the mitochondrial proliferation served to enhance oxygen diffusion rather than aerobic capacity. This contrasts sharply with our finding of substantial elevations in both muscle fiber and cristae surface density.

\section{Citrate synthase}

Active polar ectotherms are often characterized by high activity of mitochondrial enzymes such as CS and cytochrome-c oxidase (CCO) (i.e. Torres and Somero, 1988; Crockett and Sidell, 1990; Kawall et al., 2002; Lucassen, 2003; Lucassen, 2006). For instance, Kawall et al. report over three times higher CS activity in muscles and almost two times higher activity in brain tissue of Antarctic fish than in tropical species (Kawall et al., 2002). In agreement with these previous findings, we find that CS activity in the locomotory muscles of $C$. antarctica was almost four times higher than in locomotory muscles of temperate C. limacina (Fig. 4). In part, the increased activity is accounted for by the 2 -fold increase in mitochondria-rich muscle fibers in muscle bundles of $C$. antarctica and thus a higher total enzyme concentration. CS is a matrix enzyme so the elevated cristae surface density should not affect the concentration of enzymes in the mitochondria themselves. Further, the elevated cristae surface density may actually limit the space available for matrix enzymes. It may also be that CS in the polar pteropod has an increased catalytic capacity. It has been reported that some enzymes from Antarctic ectotherms are more efficient than those of warmer species (Kawall et al., 2002; Galarza-Muñoz et al., 2011). Therefore, the 4-fold difference in CS enzymatic activity between $C$. limacina and $C$. antarctica may be a result of both quantitative and qualitative changes to the enzyme. These ideas await further testing.

Although increased CS activity has been observed during cold acclimation of some eurythermal fish and invertebrates (i.e. Rodnick and Sidell, 1994; St-Pierre et al., 1998; Guderley and Leroy, 2001; Sommer and Pörtner, 2004), none was found with acclimation of C. limacina to $0^{\circ} \mathrm{C}$. There are several possible reasons for this finding. In most studies on cold acclimation in fish, the acclimation period was longer than the month-long regimen employed here, normally lasting from 6 to 8 weeks. It is possible that a longer exposure to the cold would have induced changes similar to those observed in C. limacina from the Arctic. Moreover, animals were fasted throughout the incubation, a process that may have had a negative effect on the proliferation of mitochondrial structures and proteins. 


\section{Temperature compensation at the organ and whole-animal} levels

The elevation of mitochondria and oxidative enzymes appears to result in an increased aerobic capacity for $C$. antarctica. Isolated wing-nerve preparations stimulated to contract by the addition of serotonin consumed more oxygen at $-1.8^{\circ} \mathrm{C}$ than did those from $C$. limacina at $5^{\circ} \mathrm{C}$ (Fig. 5A) ( $N=2$ for serotonin experiments). Contraction of wing muscles in whole animals is dependent on hydrostatic pressure and is linked to contraction of the heart (Arshavsky et al., 1990). Thus, muscle contractions in isolated wingnerve preparations are incomplete and presumably consume far less energy than those in actively swimming whole animals. Nevertheless, our finding of elevated oxygen consumption in coldadapted Antarctic pteropod wings is consistent with the upregulation of oxidative capacity observed at the cellular and subcellular levels. Although not yet measured in Clione spp., the cost of locomotion in some pteropods is a dominant fraction of total energy consumption in the whole animal (Davenport and Trueman, 1985). Our previous observations of elevated whole-animal oxygen consumption rates are thus not surprising (Fig. 5B) (Seibel et al., 2007). There is now wide agreement that temperature compensation does not exist at the whole-animal level in fishes (Kawall et al., 2002 and references therein). However, we hypothesize that this simply reflects the fact that most physiological processes do not require rate compensation and those that do (e.g. locomotion) are a minor component of the overall energy budget in sluggish, benthic fishes.

Maintenance of similar rates of ATP demand across a temperature gradient requires similar rates of energy consumption. Both $C$. antarctica and $C$. limacina feed exclusively on the thecosomatous pteropod genus Limacina. In fact, both species feed on L. helicina where the prey and predator populations overlap (Lalli and Gilmer, 1984). However, recent data suggest that L. helicina is not in fact a bipolar species but that substantial genetic differences exist between the northern and southern populations (Hunt et al., 2010) and we cannot rule out the possibility of different temperature sensitivities of predator-prey relationships in each hemisphere. Nevertheless, we have demonstrated here that $C$. antarctica consumes its sole prey, L. helicina, at a rate equivalent or higher than that reported previously for C. limacina (Fig. 6) (Conover and Lalli, 1972).

\section{Concluding remarks}

The observed changes in muscle and mitochondrial ultrastructure in $C$. antarctica and Arctic C. limacina clearly show up-regulation of aerobic capacity with decreasing temperature. This additional capacity appears to facilitate the maintenance of similar routine swimming rates across a temperature range and is reflected in the metabolic rates of whole animals (Seibel et al., 2007) and isolated wing muscles. In Arctic C. limacina, adaptation to cold is apparent in an increase in cristae surface densities; while in C. antarctica, compensation for cold is achieved by both the proliferation of oxidative muscle fibers (Rosenthal et al., 2009) and higher cristae surface densities. The fact that mitochondrial volume densities within oxidative muscle fibers do not change between species suggests that the observed adaptation does not result from a facilitation of oxygen diffusion between mitochondria. While in some instances the reduction of mean diffusion path length for oxygen through the tissue is advantageous for cold adaptation (Sidell, 1998), it does not seem to be a primary driver of adaptation to cold in $C$. antarctica. While increased cristae surface density may speed the diffusion of oxygen, we present a case where the need for increased aerobic capacity is clear. Thus, we hypothesize that benefit of mitochondrial enhancement for oxygen diffusion is secondary to the compensation of locomotory performance.

The difference in response to low temperature between Arctic and Antarctic Clione species may be due to differences in the temperature experienced throughout the year and the thermal history of the Arctic and Southern Oceans. In the Hornsund region, sea temperature varies from $-1.86^{\circ} \mathrm{C}$ in the winter months to $3^{\circ} \mathrm{C}$ in the summer (Weslawski et al., 1988; Walczkowski et al., 2005) whereas in McMurdo Sound water temperature never warms above $-0.5^{\circ} \mathrm{C}$ (Littlepage, 1965; Hunt et al., 2003). Although both Clione species occupy identical ecological niches in cold waters (Hunt et al., 2008), millions of years of isolation and thermal stability of Antarctic waters have led to the development of features of permanent cold adaptation in the Antarctic congener. The values we report here for mitochondrial abundance and cristae surface density in $C$. antarctica are close to theoretical upper limits and are comparable with those found in high-performance animals such as hummingbirds and tuna (Fig. 3). However, taking aerobic design to the extreme is not without a cost. For example, the high energy demand for synthesis and maintenance of mitochondria with a high cristae surface density may be associated with increased proton leak and hence higher metabolic rate and oxygen demand (Pörtner et al., 2009). More importantly, $C$. antarctica has lost the ability to swim in bursts and can maintain only the slow swimming speed of routine swimming (Rosenthal et al., 2009). We hypothesize that this loss is a direct displacement of the fast-twitch muscle fibers by oxidative muscle fibers in $C$. antarctica. While it may be that the ability to generate fast swimming is limited by the differing temperature sensitivities of fast- and slow-swimming systems (Rosenthal et al., 2009) or by the kinematics of thrust propulsion at low Reynolds numbers (Borrell et al., 2005), we have demonstrated a clear need for enhanced aerobic capacity that can, on its own, explain the loss of burst swimming.

\section{ACKNOWLEDGEMENTS}

The authors would like to thank to Dr S. Kwasniewski (PAS) for a donation of $C$. limacina from the Arctic region and both the Ocean Sciences Center at Memorial University, Newfoundland and McMurdo Station, Antarctica for their assistance in collection and maintenance of specimens and for facilitating all aspects of this work. We thank Paul Johnsen in the electron microscopy facility at U. Rhode Island for his assistance with the imaging. We thank K. Wishner and G. KassSimon for critical evaluation of this manuscript.

\section{FUNDING}

This project was funded by National Science Foundation grants OPP-9980360 (to R. Dudley) and OCE-0526493 and OPP-0538479 (to B.A.S.).

\section{REFERENCES}

Arshavsky, Y. I., Deliagina, T. G., Gelfand, I. M., Orlovsky, G. N., Panchin, Y. V., Pavlova, G. A., and Popova, L. B. (1990). Neural control of heart beat in the pteropod mollusk Clione limacina: coordination of the circulatory and locomotory systems. J. Exp. Biol. 148, 461-475.

Böer, M., Gannefors, C., Kattner, G., Graeve, M., Hop, H. and Falk-Petersen, S. (2005). The Arctic pteropod Clione limacina: seasonal lipid dynamics and life strategy. Mar. Biol. 147, 707-717.

Böer, M., Graeve, M. and Kattner, G. (2006). Impact of feeding and starvation on the lipid metabolism of the Arctic pteropod Clione limacina. J. Exp. Mar. Biol. Ecol. 328, 98-112.

Borrell, B. J., Goldbogen, J. A. and Dudley, R. (2005). Aquatic wing flapping at low Reynolds numbers: swimming kinematics of the Antarctic pteropod, Clione antarctica. J. Exp. Biol. 208, 2939-2949.

Clarke, A. (1980). A reappraisal of the concept of metabolic cold adaptation in polar marine invertebrates. Biol. J. Linn. Soc. Lond. 14, 77-92.

Clarke, A. (1983). Life in cold water: the physiological ecology of polar marine ectotherms. Oceanogr. Mar. Biol. 21, 341-453.

Conover, R. J. and Lalli, C. M. (1972). Feeding and growth in Clione limacina (Phipps), a pteropod mollusk. J. Mar. Exp. Biol. Ecol. 9, 279-302.

Conover, R. J. and Lalli, C. M. (1974). Feeding and growth in Clione limacina (Phipps), a pteropod mollusc. II. Assimilation, metabolism, and growth efficiency. $J$. Exp. Mar. Biol. Ecol. 16, 131-154.

Crockett, E. L. and Sidell, B. D. (1990). Some pathways of energy metabolism are cold adapted in Antarctic fishes. Physiol. Zool. 63, 472-488. 
Davenport, J. and Trueman, E. R. (1985). Oxygen uptake and buoyancy in zooplanktonic organisms from the tropical eastern Atlantic. Comp. Biochem. Physiol. A 81, 857-863.

Egginton, S. and Sidell, B. D. (1989). Thermal acclimation induces adaptive changes in subcellular structure of fish skeletal muscle. Am. J. Physiol. 256, R1-R9.

Elias, H. and Hyde, D. M. (1980). An elementary introduction to stereology (quantitative microscopy). Am. J. Anat. 159, 412-446.

Galarza-Muñoz, G., Soto-Morales, S. I., Holmgren, M. and Rosenthal, J. J. C. (2011). Physiological adaptation of an Antarctic $\mathrm{Na}^{+} / \mathrm{K}^{+}-\mathrm{ATP}$ ase to the cold. J. Exp. Biol. 214, 2164-2174.

Gilmer, R. W. and Lalli, C. M. (1990). Bipolar variation in Clione, a gymnosomatous pteropod. Am. Malacol. Bull. 8, 67-75.

Guderley, H. (2004). Metabolic responses to low temperature in fish muscle. Biol. Rev. Camb. Philos. Soc. 79, 409-427.

Guderley, H. and Leroy, P. H. (2001). Family origin and the response of threespine stickleback, Gasterosteus aculeatus, to thermal acclimation. J. Comp. Physiol. B 171, 91-101.

Guderley, H. and St-Pierre, J. (2002). Going with the flow or life in the fast lane: contrasting mitochondrial responses to thermal change. J. Exp. Biol. 205, 2237 2249.

Hardewig, I., van Dijk, P. L. K., Moyes, C. D. and Pörtner, H. O. (1999). Temperature-dependent expression of cytochrome-c oxidase in Antarctic and temperate fish. Am. J. Physiol. 277, R508-R516.

Hoppeler, H. and Lindstedt, S. L. (1985). Malleability of skeletal muscle in overcoming limitations: structural elements. J. Exp. Biol. 115, 355-364.

Hunt, B., Strugnell, J., Bednarsek, N., Linse, K., Nelson, R. J., Pakhomov, E., Seibel, B., Steinke, D. and Würzberg, L. (2010). Poles apart: the "bipolar" pteropod species Limacina helicina is genetically distinct between the Arctic and Antarctic oceans. PLOS ONE 5, e9835.

Hunt, B. M., Hoefling, K. and Cheng, C.-H. C. (2003). Annual warming episodes in seawater temperatures in McMurdo Sound in relationship to endogenous ice in notothenoid fish. Antarct. Sci. 15, 333-338.

Hunt, B. P. V., Pakhomov, E. A., Hosie, G. W., Siegel, V., Ward, P. and Bernard, K. (2008). Pteropods in Southern Ocean ecosystems. Prog. Oceanogr. 78, 193-221. Johnston, I. A. and Harrison, P. (1985). Contractile and metabolic characteristics of muscle fibers from Antarctic fish. J. Exp. Biol. 116, 223-236.

Johnston, I. A. and Maitland, B. (1980). Temperature acclimation in crucian carp Carassius carassius L., morphometric analyses of muscle fibre ultrastructure. J. Fish Biol. 17, 113-125.

Johnston, I. A., Calvo, J., Guderley, H., Fernandez, D. and Palmer, L. (1998). Latitudinal variation in the abundance and oxidative capacities of muscle mitochondria in perciform fishes. J. Exp. Biol. 201, 1-12.

Kawall, H. G., Torres, J. J., Sidell, B. D. and Somero, G. N. (2002). Metabolic cold adaptation in Antarctic fishes: evidence from enzymatic activities of brain. Mar. Biol. 140, 279-286.

Kilarski, W. M., Romek, M., Kozlowska, M. and Goerlich, A. (1996). Short-term thermal acclimation induces adaptive changes in the inner mitochondrial membranes of fish skeletal muscle. J. Fish Biol. 49, 1280-1290.

Lalli, C. M. and Gilmer, R. W. (1989). Pelagic Snail: The Biology of the Planktonic Gastropod Molluscs. Stanford, CA: Stanford University Press.

Littlepage, J. L. (1965). Oceanographic investigations in McMurdo Sound, Antarctica. Ant. Res. Ser. 5, 1-37.

Lucassen, M., Schmidt, A., Eckerle, L. G. and Pörtner, H. O. (2003). Mitochondrial proliferation in the permanent vs. temporary cold: enzyme activities and mRNA levels in Antarctic and temperate zoarcid fish. Am. J. Physiol. 285, R1410-R1420.

Lucassen, M., Koschnick, N., Eckerle, L. G. and Pörtner, H. O. (2006). Mitochondrial mechanisms of cold adaptation in cod (Gadus morhua L.) populations from different climatic zones. J. Exp. Biol. 209, 2462-2471.

Mathieu-Costello, O., Agey, P. J. and Logemann, R. B. (1992). Capillary-fibe geometrical relationships in tuna red muscle. Can. J. Zool. 70, 1218-1229.

Morley, S. A., Lurman, G. J., Skepper, J. N., Pörtner, H. O. and Peck, L. S. (2009) Thermal plasticity of mitochondria: A latitudinal comparisom between Southern Ocean mollusks. Comp. Biochem. Physiol. A 152, 423-430.

Moyes, C. D., Mathieu-Costello, O. A., Brill, R. W. and Hochachka, P. W. (1992) Mitochondrial metabolism of cardiac and skeletal muscles from a fast (Katsuwonas pelamis) and slow (Cyprinus cyprio) fish. Can. J. Zool. 70, 1246-1253.

Norekian, T. P. and Satterlie, R. A. (1996). Whole body withdrawal circuit and its involvement in the behavioral hierarchy of the mollusk Clione limacina. $J$. Neurophysiol. 75, 529-537.

O'Brien, K. M., Skilbeck, C., Sidell, B. D. and Egginton, S. (2003). Muscle fine structure may maintain the function of oxidative fibres in haemoglobinless Antarctic fishes. J. Exp. Biol. 206, 411-421.

Peck, L. S. (2002). Ecophysiology of marine Antarctic ectotherms: limits to life. Polar Biol. 25, 31-40

Phleger, C. F., Nichols, P. D. and Virtue, P. (1997). Lipids and buoyancy in Southern ocean pteropods. Lipids 32, 1093-1100.

Pörtner, H. O. (2002). Physiological basis of temperature-dependent biogeography: trade-offs in muscle design and performance in polar ectotherms. J. Exp. Biol. 205, 2217-2230.
Pörtner, H. O., Hardewig, I. and Peck, L. S. (1999). Mitochondrial function and critical temperature in the Antarctic bivalve Laternula elliptica. Comp. Biochem. Physiol. A 124, 179-189.

Pörtner, H. O, Peck, L. and Somero G. (2009). Thermal limits and adaptation in marine Antarctic ectotherms: an integrative view. Phil. Trans. R. Soc. B 362, 22332258.

Rodnick, K. J. and Sidell, B. D. (1994). Cold acclimation increases carnitine palmitoyltransferase I activity in oxidative muscle of striped bass. Am. J. Physiol. 266, R405-R412.

Rome, L. C. and Lindstedt, S. L. (1998). The quest for speed: muscles built for highfrequency contractions. News Physiol. Sci. 13, 261-268.

Rosenthal, J. J., Seibel, B. A., Dymowska, A. and Bezanilla, F. (2009). Trade-off between aerobic capacity and locomotor capability in an Antarctic pteropod. Proc Natl. Acad. Sci. USA 106, 6192-6196.

Satterlie, R. A. and Spencer, A. N. (1985). Swimming in the pteropod mollusc, Clione limacina: II. Physiology. J. Exp. Biol. 116, 205-222.

Satterlie, R. A., LaBarbera, M. and Spencer, A. N. (1985). Swimming in the pteropod mollusk Clione limacina. I. Behaviour and morphology. J. Exp. Biol. 166, 189-204

Satterlie, R. A., Goslow, G. E. and Reyes, A. (1990). Two types of striated muscle suggests two-geared swimming in the pteropod mollusk Clione limacina. J. Exp. Zool. 255, 131-140.

Seibel, B. A. and Dierssen, H. M. (2003). Cascading trophic impacts of reduced biomass in the Ross Sea, Antarctica: just the tip of the iceberg? Biol. Bull. 205, 9397.

Seibel, B. A., Thuesen, E. V. and Childress, J. J. (1998). Flight of the vampire: ontogenetic gait-transition in Vampyroteuthis infernalis (Cephalopoda: vampyromorpha). J. Exp. Biol. 201, 2413-2424.

Seibel, B. A., Dymowska, A. and Rosenthal, J. (2007). Metabolic temperature compensation and coevolution of locomotory performance in pteropod mollusks. Integr. Comp. Biol. 47, 880-891.

Sidell, B. D. (1980). Responses of goldfish (Carassius auratus, L.) muscle to acclimation temperature: alterations on biochemistry and proportions of different fiber types. Physiol. Zool. 53, 98-107.

Sidell, B. D. (1998). Intracellular oxygen diffusion: the roles of myoglobin and lipid at cold body temperature. J. Exp. Biol. 201, 1119-1128.

Smith, D. S. (1963). The structure of flight muscle sarcosomes in the blowfly Calliphora erythrocephala (Diptera). J. Cell Biol. 19, 115-138.

Sommer, A. M. and Pörtner, H. O. (2002). Metabolic cold adaptation in the lugworm Arenicola marinara: comparison of a North Sea and White Sea population. Mar. Ecol. Prog. Ser. 240, 171-182.

Sommer, A. M. and Pörtner, H. O. (2004). Mitochondrial function in seasonal acclimatization versus latitudinal adaptation to cold in the lugworm Arenicola marina (L.). Physiol. Biochem. Zool. 77, 174-186.

Srere, P. A. (1985). Organization of proteins within the mitochondrion. In Organized Multienzyme Systems: Catalytic Properties (ed. G. R. Welch), pp. 1-61. London, UK: Academic Press.

St-Pierre, J., Charest, P.-M. and Guderley, H. (1998). Relative contribution of quantitative and qualitative changes in mitochondria to metabolic compensation during seasonal acclimatization of rainbow trout Oncorhynchus mykiss. J. Exp. Biol. 201, 2961-2970.

Suarez, R. K. (2003). Shaken and stirred: muscle structure and metabolism. J. Exp. Biol. 206, 2021-2029.

Suarez, R. K., Lighton, J. R. B., Brown, G. S. and Mathieu-Costello, O. (1991) Mitochondrial respiration in hummingbird flight muscles. Proc. Natl. Acad. Sci. USA 88, 4870-4873.

Suarez, R. K., Staples, J. F., Lighton, J. R. B. and Mathieu-Costello, O. (2000). Mitochondrial function in flying honeybees (Apis mellifera): respiratory chain enzymes and electron flow from complex III to oxygen. J. Exp. Biol. 203, 905-911.

Thuesen, E. V. and Childress, J. J. (1994). Respiratory rates and metabolic enzyme activities of oceanic California medusae in relation to body size and habitat depth. Biol. Bull. Mar Biol. Lab. 187, 84-98.

Torres, J. J. and Somero, G. N. (1988). Metabolism, enzymatic activities and cold adaptation in Antarctic mesopelagic fishes. Mar. Biol. 98, 169-180.

Tyler, S. and Sidell, B. D. (1984). Changes in mitochondrial distribution and diffusion distances in muscle of goldfish upon acclimation to warm and cold temperatures. $J$. Exp. Zool. 232, 1-9.

Walczkowski, W., Piechura, J., Osinski, R. and Wieczorek, P. (2005). The West Spitsbergen Current volume and heat transport from synoptic observations in summer. Deep-Sea Res. 52, 1374-1391.

Weibel, E. R. (1979). Stereological methods. Practical Methods for Biological Morphology, Vol. 1. London, UK: Academic Press.

Weibel, E. R. (1985). Design and performance of muscular systems: an overview. J. Exp. Biol. 115, 405-412.

Weinstein, R. B. and Somero, G. N. (1998). Effects of temperature on mitochondrial function in the Antarctic fish Trematomus bernacchii. J. Comp. Physiol. B 168, 190

Weslawski, J. M., Zajaczkowski, M., Kwaśniewski, S., Jezierski, J. and Moskal, W. (1988). Seasonality in an Arctic fjord ecosystem: Hornsund, Spitsbergen. Polar Res. 6, 185-189. 